\title{
Effects of ECAP Extrusion on the Microstructure, Mechanical Properties and Biodegradability of $\mathrm{Mg}-2 \mathrm{Zn}-\mathrm{xGd}-0.5 \mathrm{Zr}$ Alloys
}

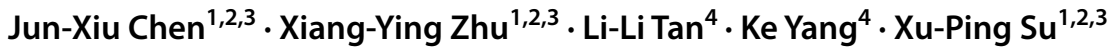

Received: 8 May 2020 / Revised: 5 July 2020 / Accepted: 11 July 2020 / Published online: 22 September 2020

(c) The Chinese Society for Metals (CSM) and Springer-Verlag GmbH Germany, part of Springer Nature 2020

\begin{abstract}
Effects of equal channel angular pressing (ECAP) extrusion on the microstructure, mechanical properties and biodegradability of $\mathrm{Mg}-2 \mathrm{Zn}-x \mathrm{Gd}-0.5 \mathrm{Zr}(x=0,0.5,1,2 \mathrm{wt} \%)$ alloys were studied in this work. Microstructure analysis, tensile test at ambient temperature, immersion test and electrochemical test in Hank's solution were carried out. The results showed that Gd could further enhance the grain refinement during the ECAP extrusion. Both Gd addition and ECAP extrusion could improve the mechanical properties of the alloys, and the extrusion played the dominant role. Minor addition of Gd $(0.5-1 \mathrm{wt} \%)$ could obviously enhance the corrosion resistance of the alloys. To some extent, ECAP extrusion improved the corrosion resistance of the alloys due to the change of second phases distribution and the refinement of grains. Further increase in extrusion pass was detrimental to the improvement of the corrosion resistance as a result of increment of the grain boundaries.
\end{abstract}

Keywords Mg alloys $\cdot$ Gd addition $\cdot$ ECAP extrusion pass $\cdot$ Mechanical property $\cdot$ Biodegradable behavior

\section{Introduction}

In recent years, extensive researches on biodegradable magnesium (Mg) and its alloys have been carried out. Both in vitro and in vivo studies have proved that $\mathrm{Mg}$ alloys not only have good biocompatibility but also can promote the bone growth during their degradation $[1,2]$. Until now, $\mathrm{Mg}$ and its alloys in clinical applications have gained some significant achievements. The Syntellix Co. in Germany was

Available online at http://link.springer.com/journal/40195.

Li-Li Tan

lltan@imr.ac.cn

$\triangle$ Xu-Ping Su

sxping@cczu.edu.cn

1 Key Laboratory of Materials Surface Science and Technology of Jiangsu Province, Changzhou University, Changzhou 213164, China

2 Jiangsu Collaborative Innovation Center of Photovoltaic Science and Engineering, Changzhou University, Changzhou 213164, China

3 National Experimental Teaching Demonstration Center of Materials Science and Engineering, Changzhou University, Changzhou 213164, China

4 Institute of Metal Research, Chinese Academy of Sciences, Shenyang 110016, China awarded the CE mark for using $\mathrm{Mg}-\mathrm{Y}-\mathrm{RE}-\mathrm{Zr}$ alloy screw product to treat the hallux valgus surgery in 2013 [3]. After that, the Magmaris (Biotronik AG, Bulach, Switzerland) stent product in 2016 also received the CE mark [4]. However, the key problem limiting their wide clinical applications is the poor corrosion resistance [5]. High degradation rate can lead to premature failure of the implant. Furthermore, the high alkaline environment caused by implants degradation may lead to toxicity and infection [6]. Thus it is important to regulate the degradation rate of $\mathrm{Mg}$ alloys, especially for orthopedic applications. Mechanical property is another important factor that has to be considered. The strength of $\mathrm{Mg}$ alloys is much lower than those of some stainless steels and titanium alloys. In some clinics, $\mathrm{Mg}$ alloys are also limited in load-bearing applications. Alloying and plastic deformation are usually used to improve the mechanical properties and corrosion resistance of $\mathrm{Mg}$ alloys.

Alloying is one of the effective methods to enhance both the mechanical property and corrosion resistance of $\mathrm{Mg}$ alloys. $\mathrm{Gd}$, a rare earth element, is often added into $\mathrm{Mg}$ alloys [7-9]. It has good strengthening effect due to its high solid solubility in $\mathrm{Mg}$ [10]. Recent research showed that a $\mathrm{Mg}-\mathrm{Zn}-\mathrm{Gd}-\mathrm{Zr}$ alloy exhibited good mechanical properties and corrosion resistance [11]. Therefore, $\mathrm{Mg}-\mathrm{Zn}-\mathrm{Gd}-\mathrm{Zr}$ alloys have attracted much attention. 
It has been proved that plastic deformation not only has good grain refinement effect but also can make the dendritic second phases into small particles in Mg alloys [12-15], which is beneficial to the enhancement of mechanical properties and corrosion resistance. Plastic deformation, especially severe plastic deformation (SPD), is an effective way to improve mechanical property and corrosion resistance of $\mathrm{Mg}$ alloys $[16,17]$. Equal channel angular pressing (ECAP) is one kind of SPD deformation. ECAP can obviously decrease the grain size of $\mathrm{Mg}$ alloys $[18,19]$. After four passes ECAP extrusions, the grain size of AZ31 alloy decreased from 47 to $1-5 \mu \mathrm{m}$ [20]. The excellent grain refinement effect leads to the great enhancement of the ductility of $\mathrm{Mg}$ alloys.

Until now, less study was found about the effect of ECAP extrusion on the biodegradable behavior of $\mathrm{Mg}-\mathrm{Zn}-\mathrm{Gd}-\mathrm{Zr}$ alloy. Moreover, there are few studies to illustrate the effect of $\mathrm{Gd}$ content on the microstructure, mechanical properties and biodegradability of the $\mathrm{Mg}-2 \mathrm{Zn}-0.5 \mathrm{Zr}$ alloy during the plastic deformation. In this work, effects of ECAP extrusion on the microstructure, mechanical properties and biodegradability of $\mathrm{Mg}-2 \mathrm{Zn}-x \mathrm{Gd}-0.5 \mathrm{Zr}(x=0,0.5,1,2 \mathrm{wt} \%)$ alloys were studied.

\section{Experimental}

Chemical compositions of the $\mathrm{Mg}-\mathrm{Zn}-x \mathrm{Gd}-\mathrm{Zr}$ alloys are listed in Table 1. Bars of $10 \mathrm{~mm} \times 10 \mathrm{~mm} \times 100 \mathrm{~mm}$ were cut from the ingots. Then, they were heat treated before extrusion at $400{ }^{\circ} \mathrm{C}$ for $8 \mathrm{~h}$. After heat treatment, the bars were put into the ECAP mould (Fig. 1a) and were extruded after heating at $380{ }^{\circ} \mathrm{C}$ for $1.5 \mathrm{~h}$. The ECAP mould channel is $10 \mathrm{~mm} \times 10 \mathrm{~mm}$. Four passes extrusion were carried out. After each extrusion, the mould was open immediately and the bars were taken out. Then the bars were rotated $90^{\circ}$ in the same direction and the next extrusion was performed. The bars after one pass, two passes and four passes extrusion were carefully analyzed.

Samples of $10 \mathrm{~mm} \times 10 \mathrm{~mm} \times 5 \mathrm{~mm}$ cut from the extruded bars were etched in a picric acid solution which contains $70 \mathrm{~mL}$ ethanol, $10 \mathrm{~mL}$ acetic, $6 \mathrm{~g}$ picric and $10 \mathrm{~mL}$ water.

Table 1 Chemical compositions of $\mathrm{Mg}-\mathrm{Zn}-x \mathrm{Gd}-\mathrm{Zr}$ alloys

\begin{tabular}{lllll}
\hline Alloys & \multicolumn{4}{l}{ Actual composition } \\
\cline { 2 - 5 } & $\mathrm{Zn}(\mathrm{wt} \%)$ & $\mathrm{Gd}(\mathrm{wt} \%)$ & $\mathrm{Zr}(\mathrm{wt} \%)$ & $\mathrm{Mg}$ \\
\hline Mg-2Zn-0.5Zr (0Gd) & 2.22 & - & 0.40 & $\mathrm{Bal}$. \\
$\begin{array}{l}\text { Mg-2Zn-0.5Gd-0.5Zr } \\
\quad(0.5 \mathrm{Gd})\end{array}$ & 2.00 & 0.53 & 0.48 & $\mathrm{Bal}$. \\
Mg-2Zn-1Gd-0.5Zr (1Gd) & 2.07 & 0.95 & 0.48 & $\mathrm{Bal}$. \\
$\mathrm{Mg}-2 \mathrm{Zn}-2 \mathrm{Gd}-0.5 \mathrm{Zr}(2 \mathrm{Gd})$ & 2.24 & 1.90 & 0.47 & $\mathrm{Bal}$. \\
\hline
\end{tabular}
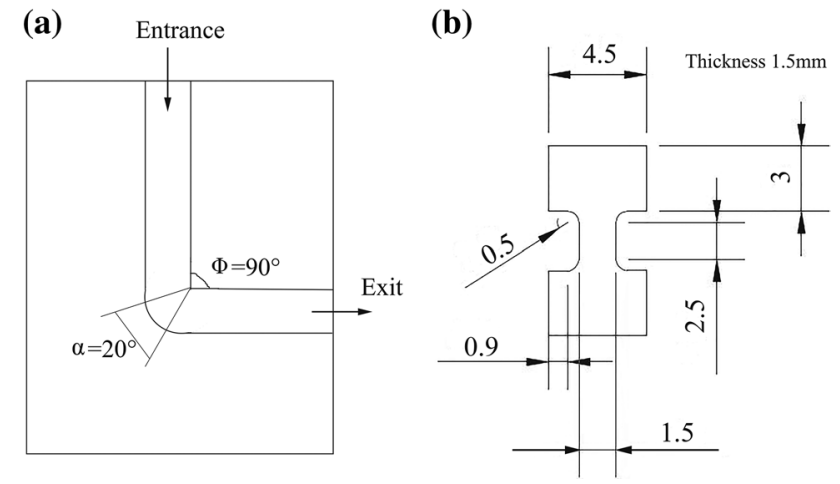

Fig. 1 Schematic illustrations of a ECAP extrusion mould, b dimension of tensile test specimen

The grain size was measured by straight-line cutting point method. Microstructure observation was performed using an optical microscope and a scanning electron microscope (SEM, S-3400N). After two passes and four passes extrusion, the tensile test was performed using an Instron-5569 universal testing machine with tensile rate of $1.0 \mathrm{~mm} \mathrm{~min}^{-1}$ at room temperature. The dimension of tensile sample is shown in Fig. 1b. Three samples were prepared for each testing material. Hardness measurement of the samples after one pass, two passes and four passes extrusion were carried out using a microhardness tester (HVT-1000). For each material, the hardness measurement was repeated five times.

Samples with size of $10 \mathrm{~mm} \times 10 \mathrm{~mm} \times 2 \mathrm{~mm}$ were prepared for the immersion test. They were immersed in Hank's solution $\left(37^{\circ} \mathrm{C}\right.$ and $\mathrm{pH}$ 7.4) for 14 days according to the immersion ratio of $1.25\left(\mathrm{~cm}^{2} \mathrm{~mL}^{-1}\right)$ (ISO 1099312 standard) in plastic tubes. In order to keep the Hank's solution fresh, it was changed every day. The $\mathrm{pH}$ value of the solution was measured for 14 days. The higher the $\mathrm{pH}$ value of the solution, the lower the corrosion resistance of the alloy. After 14 days immersion, the samples were taken out and cleaned in a solution of chromium trioxide to remove the surface products. After that the degradation rate was calculated using Eq. (1) [21]:

$P_{\mathrm{i}}=\frac{K W}{A T D}$

where $K$ represents a coefficient with value of $8.76 \times 10^{4} ; \mathrm{W}$ represents the sample weight loss during 2 weeks immersion period (g); $A$ represents the surface area of sample before immersion $\left(\mathrm{cm}^{2}\right) ; T$ represents the immersion time (h) $(14$ days $=336 \mathrm{~h}) ; D$ represents the density of the $\mathrm{Mg}$ alloys $\left(1.74 \mathrm{~g} \mathrm{~cm}^{-3}\right)$. Finally, the corrosion morphologies on samples were observed by SEM.

Samples were molded in epoxy resin with one side surface $(10 \mathrm{~mm} \times 10 \mathrm{~mm})$ outside for electrochemical 
experiment. The experiment was carried out at $37{ }^{\circ} \mathrm{C}$ in Hank's solution [22] by using Gamry Instruments (Reference 600). Saturated calomel electrode ( $\mathrm{SCE}, \mathrm{Hg} / \mathrm{Hg}_{2} \mathrm{Cl}_{2} /$ saturated $\mathrm{KCl}$ ) was the reference electrode. Platinum plate electrode as the cathode in the reaction was the counter electrode and the sample as the anode in the reaction with area of $1 \mathrm{~cm}^{2}$ outside was the working electrode. After half an hour open circuit potential (OCP) measurement and the electrochemical impedance spectroscopy (EIS) measurement were performed. The frequency range was set from $10^{5}$ to $10^{-2} \mathrm{~Hz}$. After that potentiodynamic polarization measurement started from $-250 \mathrm{mV}$ below the OCP at a scan rate of $0.5 \mathrm{mV} \mathrm{s}^{-1}$. For each testing material, three times were repeated.

\section{Results}

\subsection{Microstructures}

Figure 2 presents the optical images of the alloys after four passes extrusion and Fig. 3 shows the grain size of the alloys after extrusion. It was found that increasing the extrusion pass decreased the grain size significantly from $\sim 50 \mu \mathrm{m}$ (ascast) down to $<5 \mu \mathrm{m}$ (four passes). Moreover, addition of Gd could further enhance the grain refinement. Under the same extrusion pass, the grain size decreased with increment of the Gd content. After four passes extrusion, the alloy with $2 \mathrm{wt} \%$ Gd exhibited uniform grain size of about $2 \mu \mathrm{m}$. The grain size decreased greatly from the as-cast to the two passes extrusion; however, it decreased not obviously from the two passes extrusion to the four passes extrusion. That was mainly because when the extrusion temperature was

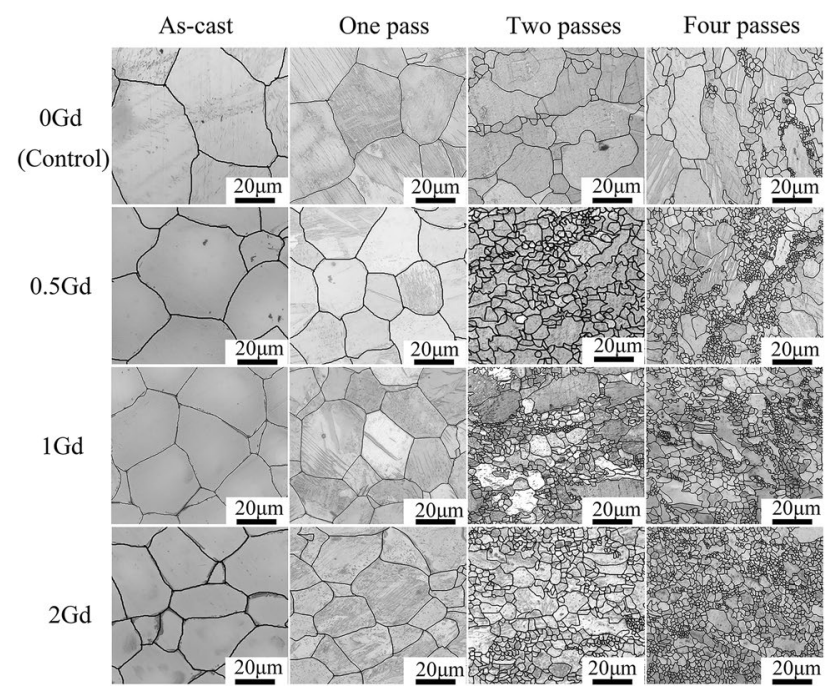

Fig. 2 Optical images of $\mathrm{Mg}-2 \mathrm{Zn}-x \mathrm{Gd}-0.5 \mathrm{Zr}$ alloys after four passes extrusion, respectively

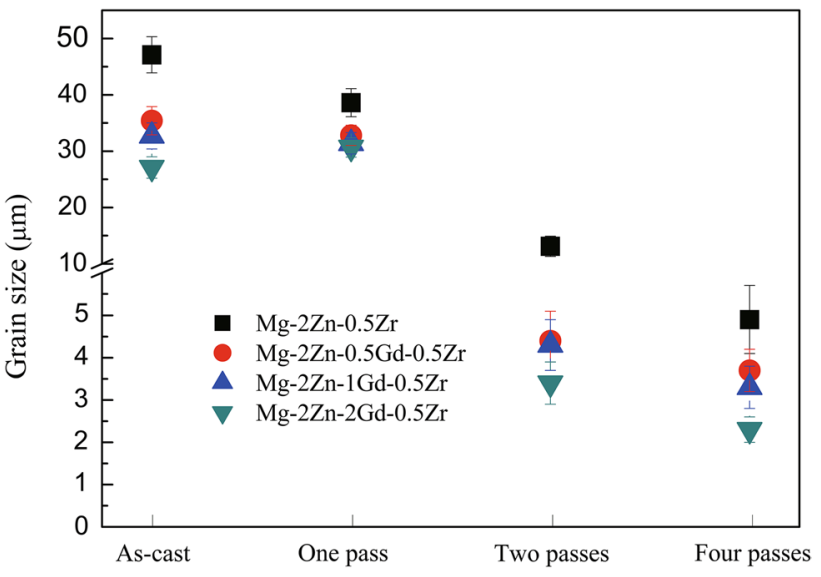

Fig. 3 Change of the grain size with the extrusion pass

high, the dynamic recrystallization occurred. After two passes extrusion, a typical bimodal grain structure formed. Some fine grains were observed after four passes extrusion. Although the grain size decreased, the coarse and fine grains were coexistent. Figure 4 presents the microstructures of the alloys. In the as-cast alloys, most of the second phases particles were distributed along the grain boundaries. When the volume fraction of second phases was high, a network structure was formed. After ECAP extrusion, the network structures of the second phases were broken. Their morphologies changed from network to granular shape. When the $\mathrm{Gd}$ content was high, even after four passes extrusion, many second phase enriched regions were observed (Fig. 4). Figure 5 shows the energy disperse spectroscopy (EDS) analyses of the spots marked in Fig. 4. According to the previous study [23], when the $\mathrm{Zn} / \mathrm{Gd}$ (wt\%) ratio was between 1.10 and 4.38 , the main second phases were I-phase $\left(\mathrm{Mg}_{3} \mathrm{GdZn}_{6}\right)$ and $\mathrm{W}$-phase $\left(\mathrm{Mg}_{3} \mathrm{Gd}_{2} \mathrm{Zn}_{3}\right)$. When the ratio was below 1.10 , the

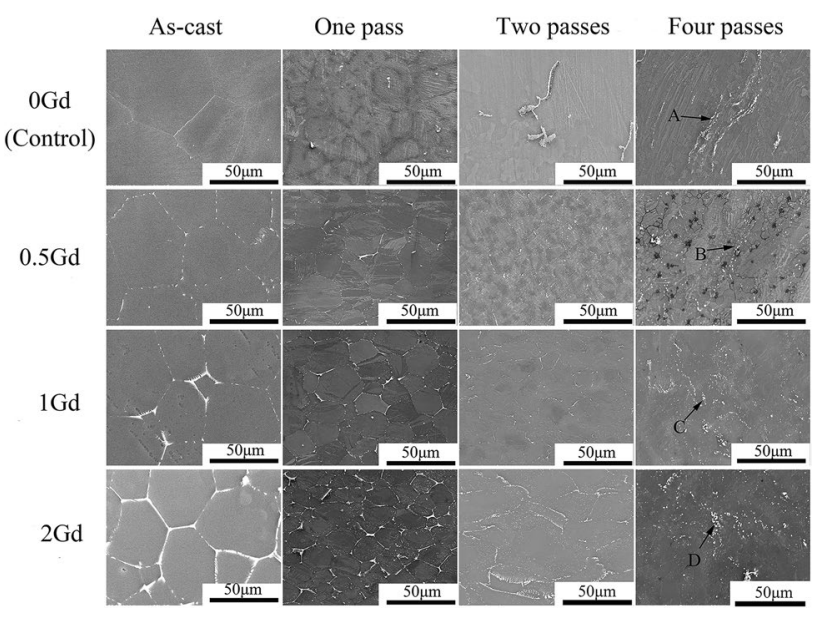

Fig. 4 SEM images of $\mathrm{Mg}-2 \mathrm{Zn}-x \mathrm{Gd}-0.5 \mathrm{Zr}$ alloys after four passes extrusion 

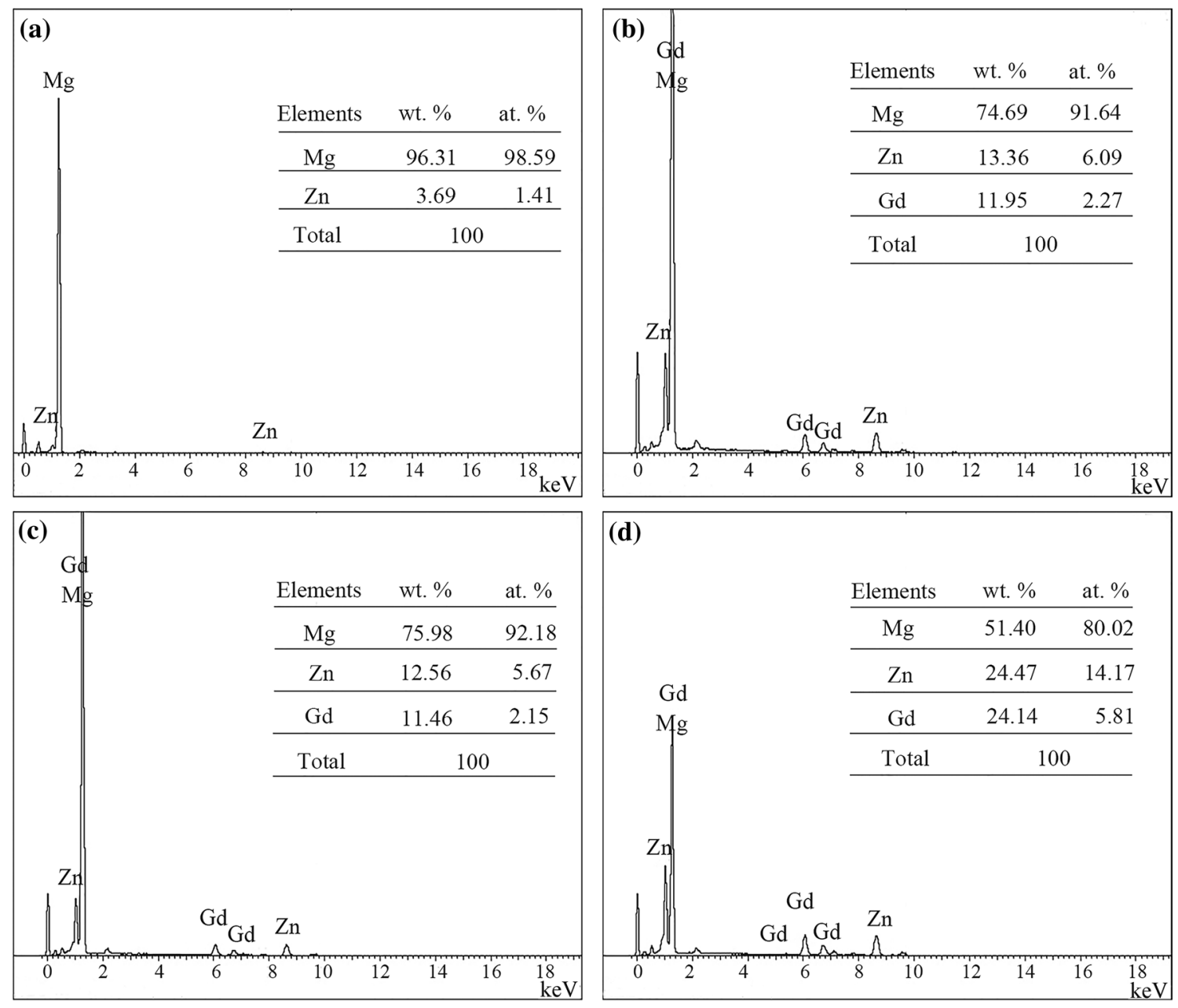

Fig. 5 EDS analyses of the spots marked in Fig. 4: a spot A, b spot B, $\mathbf{c}$ spot C, $\mathbf{d}$ spot D

main second phase was $\mathrm{W}$-phase. Therefore, it was inferred that the main second phases were I-phase and W-phase in $\mathrm{Mg}-2 \mathrm{Zn}-0.5 \mathrm{Gd}-0.5 \mathrm{Zr}$ alloy. The main second phase in $\mathrm{Mg}-2 \mathrm{Zn}-1 \mathrm{Gd}-0.5 \mathrm{Zr}$ and $\mathrm{Mg}-2 \mathrm{Zn}-2 \mathrm{Gd}-0.5 \mathrm{Zr}$ alloys was W-phase. Figure 6 presents the textures of the alloys after four passes extrusion. The main fiber texture in the $0 \mathrm{Gd}$ alloy was $\{1010\}$. When the Gd content was $0.5 \mathrm{wt} \%$ and $1 \mathrm{wt} \%$, the main fiber texture was $\{2110\}$. But for the $1 \mathrm{Gd}$ alloy, there was a certain degree of deviation. When the $\mathrm{Gd}$ content was $2 \mathrm{wt} \%$, the main fiber texture was changed to $\{2111\}$, indicating an activation of $\langle c+a>$ slip. Comparing the texture intensity, the $1 \mathrm{Gd}$ alloy exhibited the lowest texture intensity.

\subsection{Mechanical Properties}

Figure 7 presents the mechanical properties of the alloys after four passes extrusion. With increase in the extrusion pass, mechanical properties of all the alloys were improved significantly. Compared with the two passes extrusion alloys, the ultimate tensile strength (UTS), yield strength (YS) and elongation (EL) of the 1Gd alloy after four passes extrusion were increased by about $17 \%, 30 \%$ and $60 \%$, respectively. Moreover, under the same extrusion pass, the mechanical properties of the alloys increased with the increment of the Gd content. After four passes extrusion, UTS, YS and EL of the $2 \mathrm{Gd}$ alloy increased to about $280 \mathrm{MPa}, 230 \mathrm{MPa}$ and $33 \%$, respectively. Furthermore, compared with the 0Gd alloy, UTS, YS and EL of the 2 Gd alloy were increased by about $22 \%, 35 \%$ and $18 \%$, respectively. This indicates that the mechanical properties of the alloys could be improved by increasing both the ECAP extrusion pass and the Gd content. However, it was the severe plastic deformation that played the dominant role. After four passes extrusion, although 2Gd alloy exhibited the highest UTS, YS, EL and hardness, there was no much significant difference among $0.5 \mathrm{Gd}$ alloy, $1 \mathrm{Gd}$ alloy and $2 \mathrm{Gd}$ alloy. However, compared the alloys after two passes extrusion, the mechanical properties of the alloys after four passes extrusion were greatly enhanced. Figure 8 presents the relationship between the 
(a)

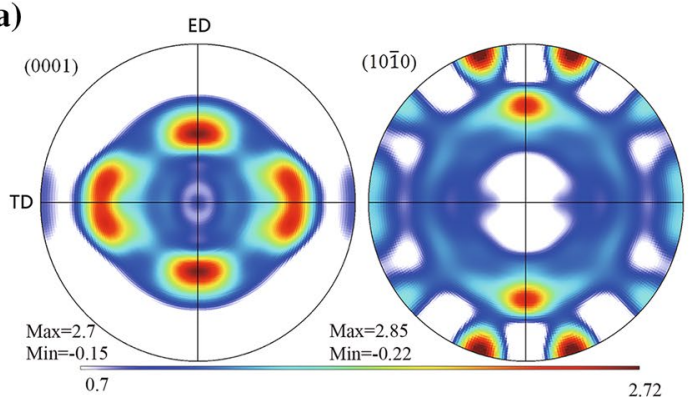

(c)

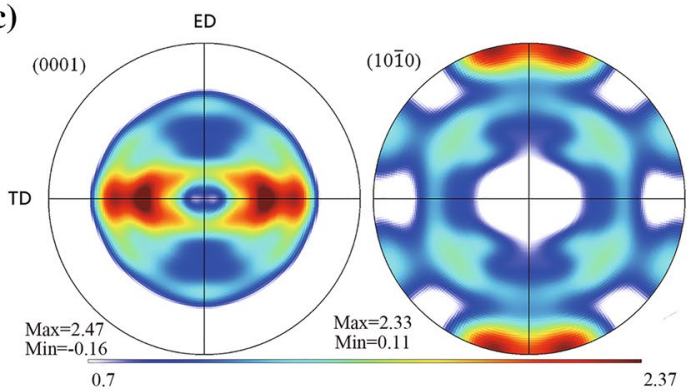

(b)

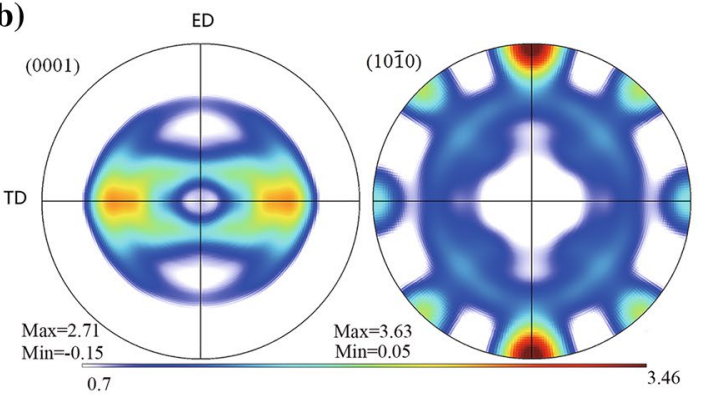

(d)

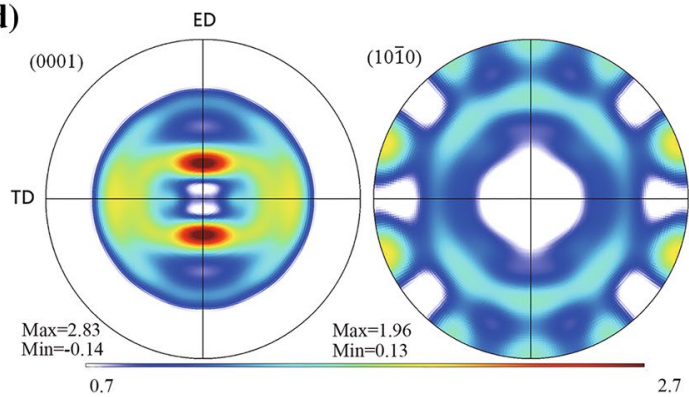

Fig. 6 Textures in the $\mathrm{Mg}-2 \mathrm{Zn}-x \mathrm{Gd}-0.5 \mathrm{Zr}$ alloys after four passes extrusion: a $0 \mathrm{Gd}, \mathbf{b} 0.5 \mathrm{Gd}, \mathbf{c} 1 \mathrm{Gd}, \mathbf{d} 2 \mathrm{Gd}$
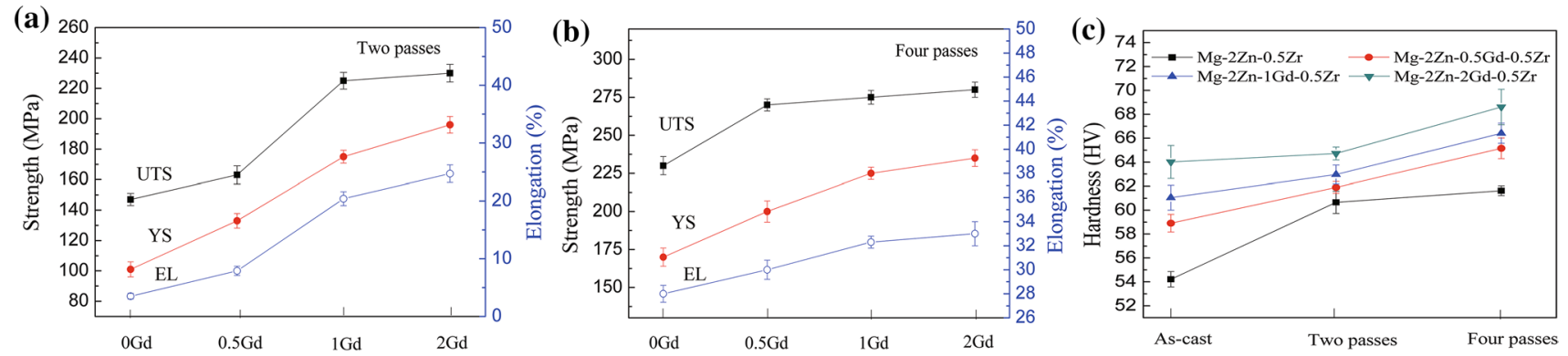

Fig. 7 Mechanical properties of Mg-2Zn- $x \mathrm{Gd}-0.5 \mathrm{Zr}$ alloys: a UTS, YS and EL of the alloys after two passes extrusion, b UTS, YS and EL of the alloys after four passes extrusion, $\mathbf{c}$ hardness of alloys after four passes extrusion

grain size $\left(d^{-\frac{1}{2}}\right)$ and the YS of the $2 \mathrm{Gd}$ alloy after the two and four passes extrusion. It can be fitted by $Y=60.22+0.25 d^{-1 / 2}$. According to the Hall-Petch relation, $\sigma_{0.2}=\sigma_{0}+k d^{-1 / 2}$, it can be inferred that the $k$ value of the alloys was 0.25 . Figure 9 shows the fracture morphologies of the alloys after four passes extrusion. All the alloys exhibited ductile fracture with many dimples. The toughness of the alloys increased with the increment of Gd content. Fracture morphologies changed from flat surface to rough surface, indicating the increase in ductility.

\subsection{Immersion Test}

The $\mathrm{pH}$ change of the solution during the immersion period is shown in Fig. 10. It can be seen that the increase in the extrusion pass decreased the $\mathrm{pH}$ values of the alloys to some extent, indicating that the corrosion resistance of the alloys was improved due to the grain refinement and composition uniform. However, with further increase in extrusion pass, the $\mathrm{pH}$ value of the solution was increased, indicating that the corrosion resistance of the alloys was decreased. Under the same extrusion pass, the $1 \mathrm{Gd}$ alloy exhibited the best corrosion resistance and the $\mathrm{pH}$ value of the solution was the lowest throughout the immersion periods. The corrosion rates of the alloys after 14 days immersion are shown in Fig. 11. It can be seen that the corrosion rates of the alloys after two passes extrusion were lower than those after four passes extrusion. After two passes extrusion, the $1 \mathrm{Gd}$ alloy showed the lowest corrosion rate of $0.5 \mathrm{~mm} \mathrm{y}^{-1}$. However, after four passes extrusion, the corrosion rate of the $1 \mathrm{Gd}$ alloy was about $1.4 \mathrm{~mm} \mathrm{y}^{-1}$ 


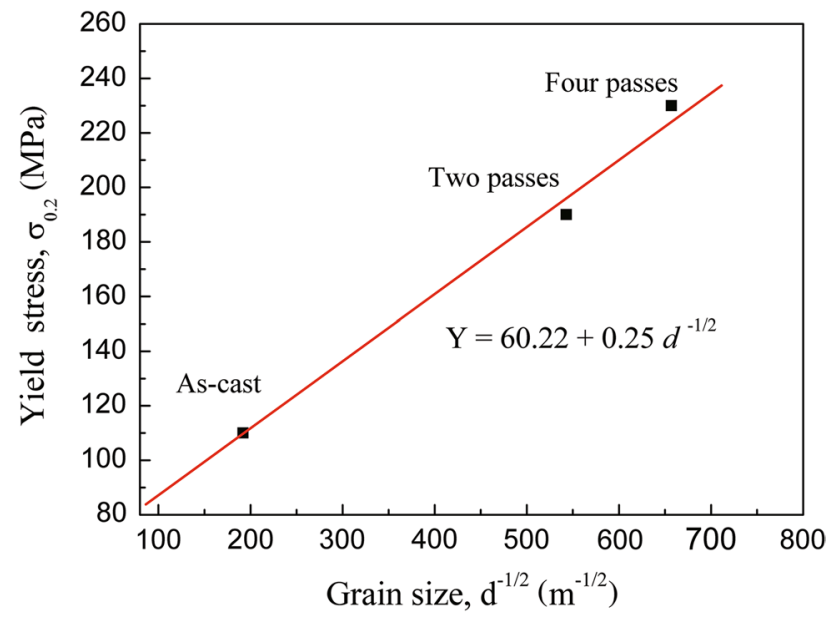

Fig. 8 Grain size dependencies of yield strength $\sigma_{0.2}$ of the $2 \mathrm{Gd}$ alloy (As-cast [11])

which was about 3 times higher than that after two passes extrusion. Figure 12 presents the microstructures of the alloys after immersion. It can be seen that after two passes extrusion, the alloys exhibited more uniform corrosions. However, the as-cast and the four passes extruded alloys exhibited severe pitting corrosion. Moreover, from the observation of the four passes cross section morphologies, it can be seen that $1 \mathrm{Gd}$ alloy showed much more uniform corrosion than other alloys without deep pits.

\subsection{Electrochemical Behavior}

The potentiodynamic polarization curves of the alloys are shown in Fig. 13. Table 2 lists the Tafel fitting results based on the potentiodynamic polarizations curves. The corrosion current density of the alloys was greatly decreased due to the severe deformation compared with that of the as-cast alloys before two passes extrusion. Further increase in the extrusion pass to four, the corrosion current density of the alloys was increased. This means that the corrosion resistance of the alloy could be improved with the increase in the severe plastic deformation to some extent. However, further increase in the severe plastic deformation was detrimental to the corrosion resistance. Under the same extrusion pass, the $1 \mathrm{Gd}$ alloy exhibited the lowest corrosion current density. For the two passes extrusion alloys, the second phases were broken into small particles which were uniformly distributed in the alloy, exhibiting a uniform corrosion. In order to investigate the corrosion mechanism, the alloys after four passes extrusion were studied by EIS. Figure 14 shows the EIS curves and the equivalent circuit. One capacitive loop and one inductive loop were observed at high frequency and low frequency, respectively, indicating that the corrosion
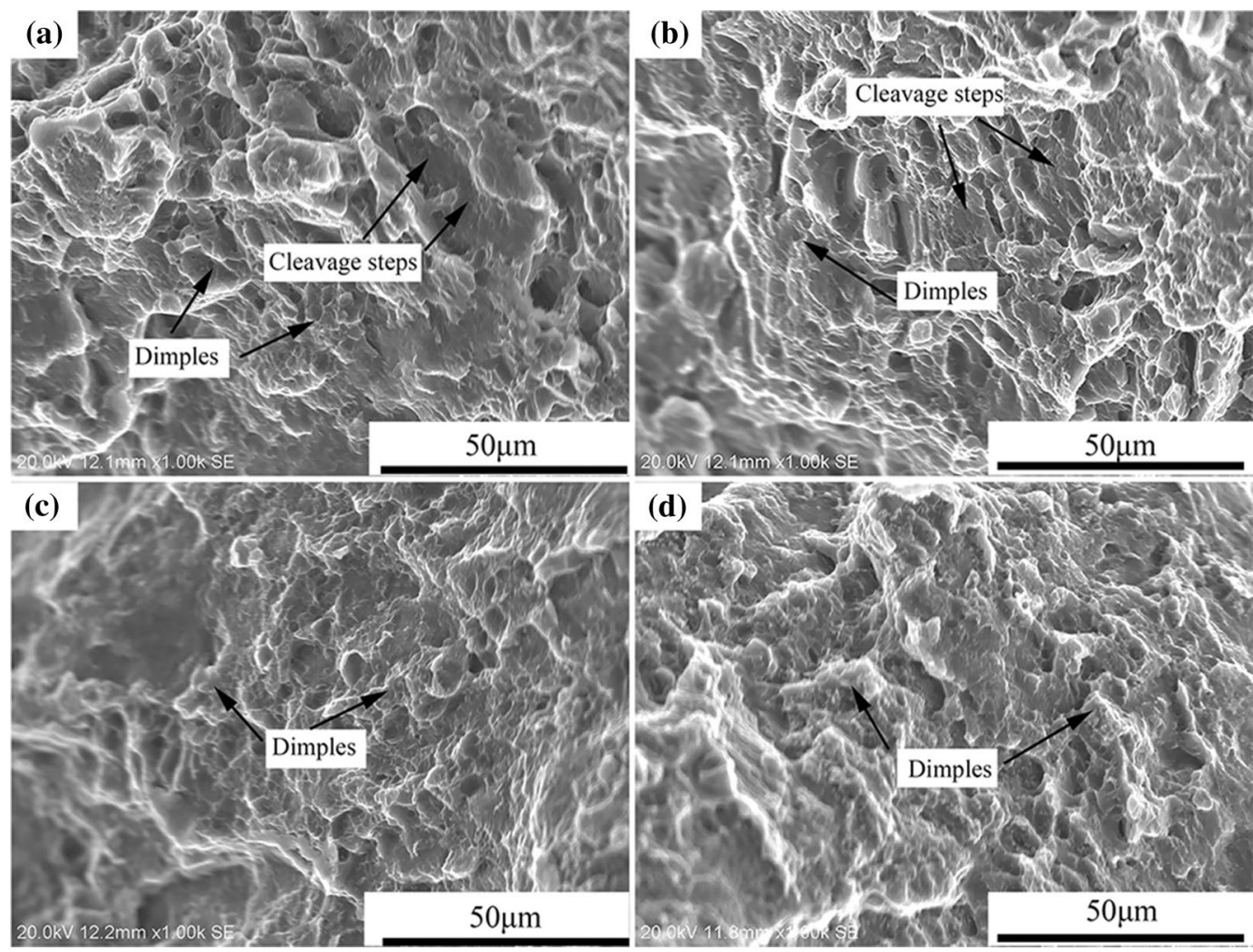

Fig. 9 Fracture morphologies of $\mathrm{Mg}-2 \mathrm{Zn}-x \mathrm{Gd}-0.5 \mathrm{Zr}$ alloys after four passes extrusion: a $0 \mathrm{Gd}, \mathbf{b} 0.5 \mathrm{Gd}, \mathbf{c} 1 \mathrm{Gd}, \mathbf{d} 2 \mathrm{Gd}$ 

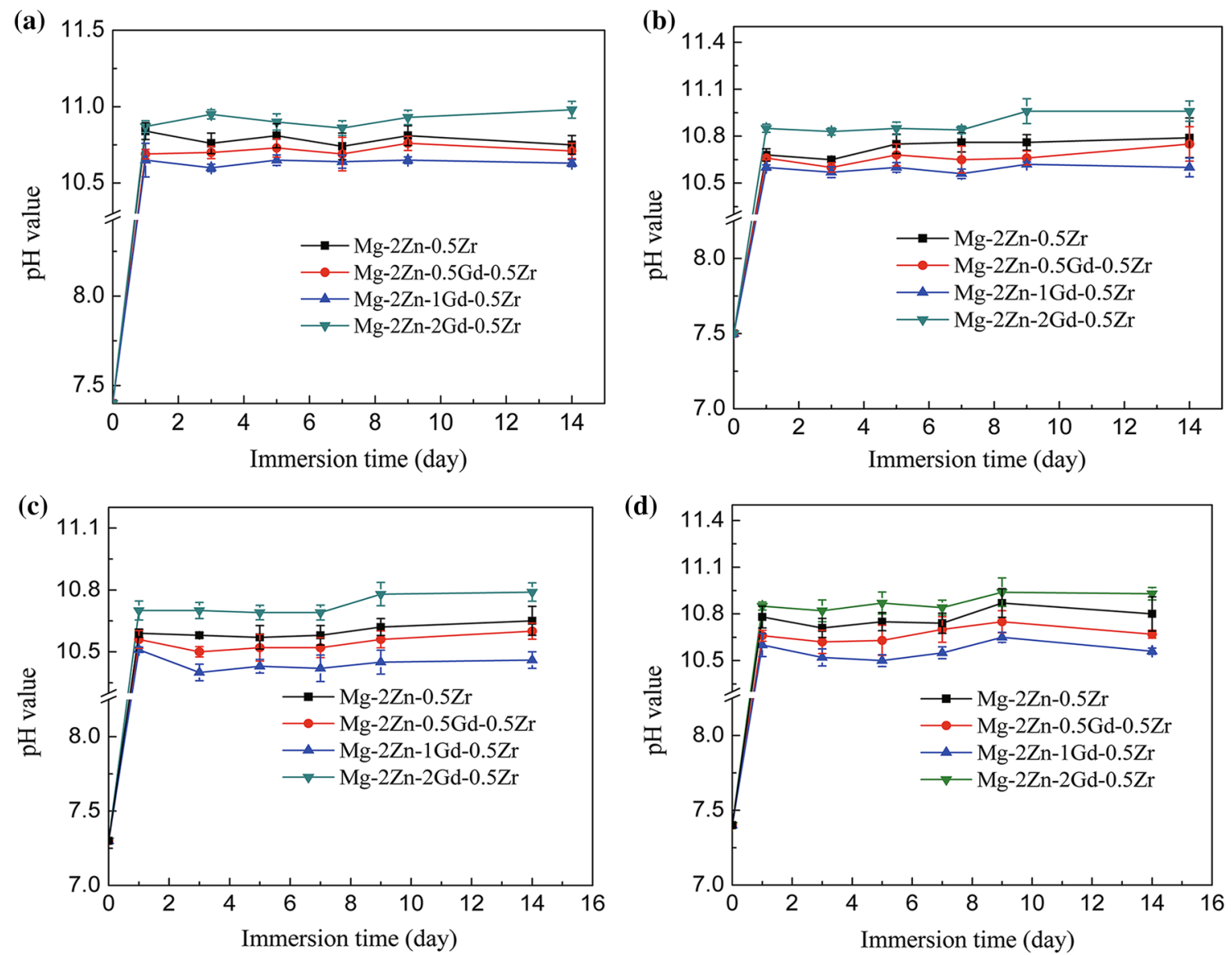

Fig. $10 \mathrm{pH}$ change of Hank's solution at different immersion time for $\mathrm{Mg}-2 \mathrm{Zn}-x \mathrm{Gd}-0.5 \mathrm{Zr}$ alloys after extrusion: $\mathbf{a}$ as-cast, $\mathbf{b}$ one pass extrusion, $\mathbf{c}$ two passes extrusion, $\mathbf{d}$ four passes extrusion

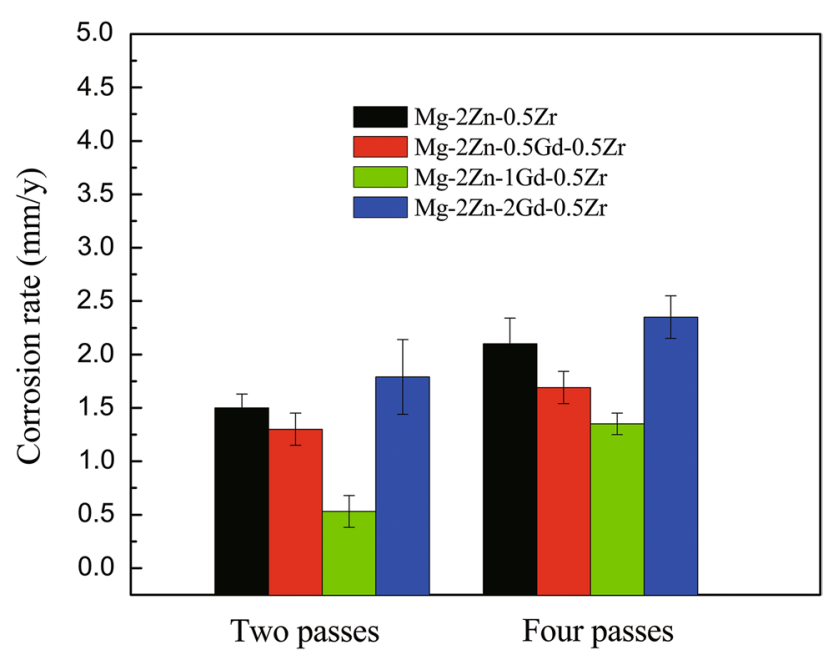

Fig. 11 Corrosion rates of the alloys immersed in Hank's solution for 14 days after two passes and four passes extrusion

mechanisms of the alloys were similar (Fig. 14a). The higher values of bode curve at low frequency and the phase angle indicate both better corrosion resistance and smoother

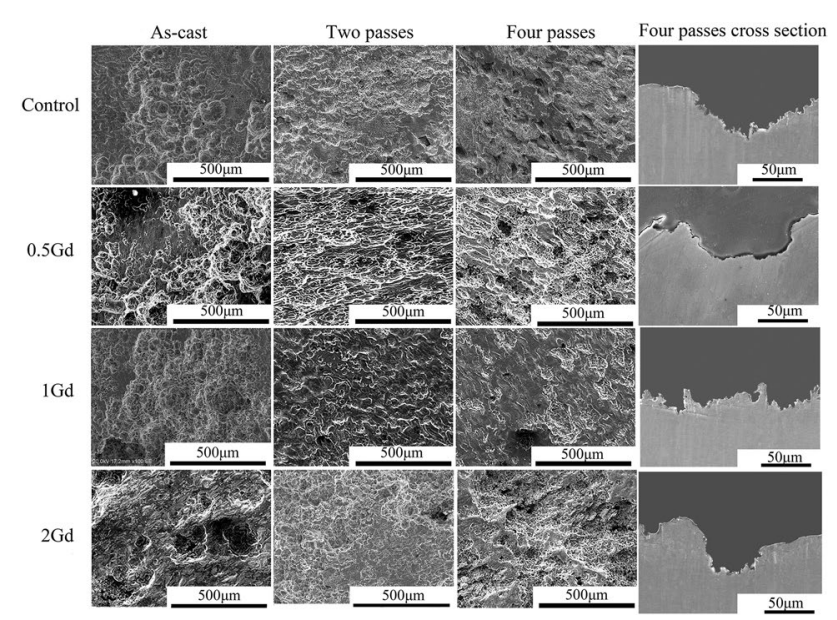

Fig. 12 Microstructures of $\mathrm{Mg}-2 \mathrm{Zn}-x \mathrm{Gd}-0.5 \mathrm{Zr}$ alloys after immersion in Hank's solution for 14 days

corrosion surface. Therefore, it could be seen that the $1 \mathrm{Gd}$ alloy exhibited the best corrosion resistance (Fig. 14b, c). Gamry Echem Analyst software was used to fit the EIS curves and the fitting errors were less than $5 \% . R_{\mathrm{S}}$ represents 
(a)

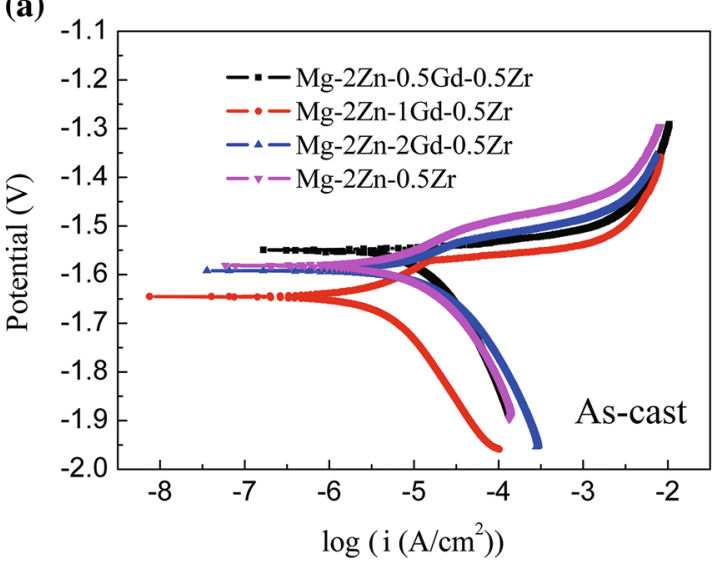

(c)

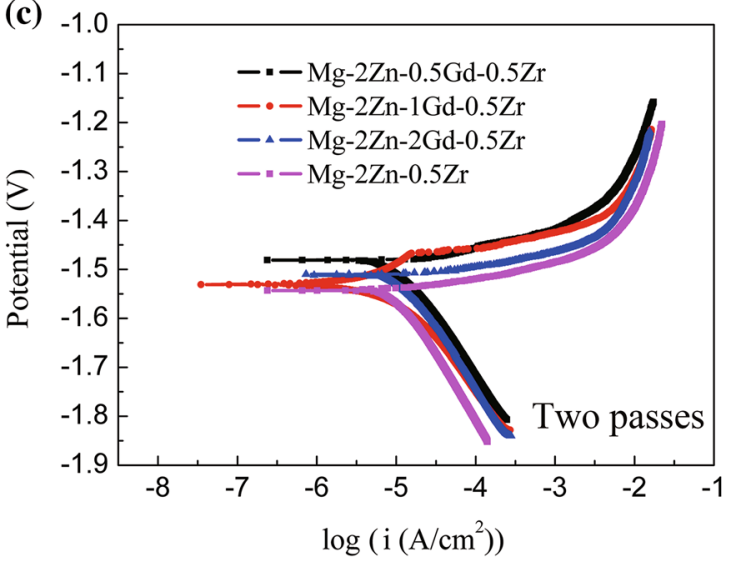

(b)

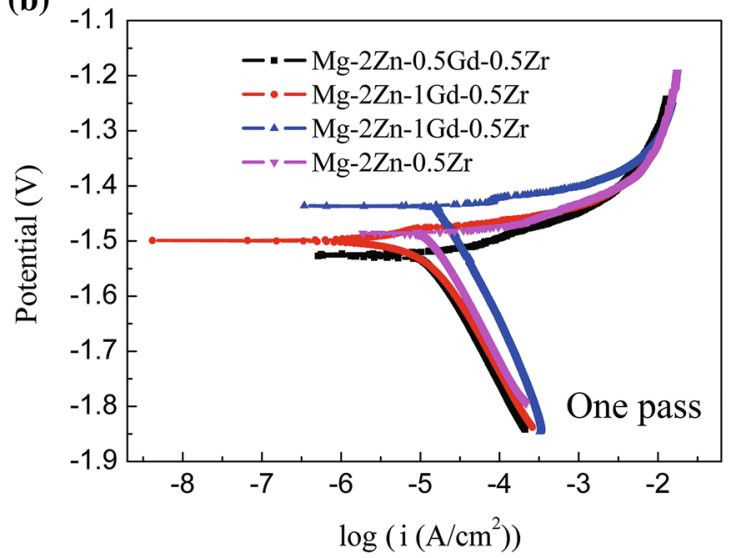

(d)

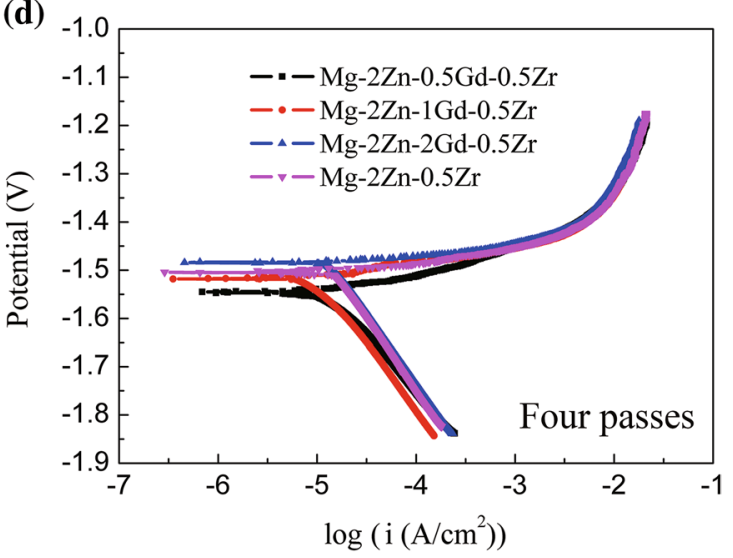

Fig. 13 Potentiodynamic polarization curves of the alloys with different extrusion passes in Hank's solution: a as-cast, $\mathbf{b}$ one pass, $\mathbf{c}$ two passes, d four passes

Table 2 Tafel fitting results based on potentiodynamic polarizations in Hank's solution

\begin{tabular}{|c|c|c|c|c|c|c|c|c|}
\hline \multirow[t]{2}{*}{ Alloys } & \multicolumn{2}{|l|}{ As-cast } & \multicolumn{2}{|l|}{ One pass } & \multicolumn{2}{|l|}{ Two passes } & \multicolumn{2}{|l|}{ Four passes } \\
\hline & $E_{\text {corr }}(\mathrm{V})$ & $i_{\text {corr }}\left(\mathrm{A} \mathrm{cm}^{-2}\right)$ & $E_{\text {corr }}(\mathrm{V})$ & $i_{\text {corr }}\left(\mathrm{A} \mathrm{cm}^{-2}\right)$ & $E_{\text {corr }}(\mathrm{V})$ & $i_{\text {corr }}\left(\mathrm{A} \mathrm{cm}^{-2}\right)$ & $E_{\text {corr }}(\mathrm{V})$ & $i_{\text {corr }}\left(\mathrm{A} \mathrm{cm}^{-2}\right)$ \\
\hline 0Gd & $-1.57 \pm 0.03$ & $20.22 \pm 1.53$ & $-1.51 \pm 0.02$ & $14.62 \pm 0.83$ & $-1.55 \pm 0.04$ & $10.52 \pm 0.30$ & $-1.50 \pm 0.01$ & $14.84 \pm 0.18$ \\
\hline $0.5 \mathrm{Gd}$ & $-1.55 \pm 0.01$ & $18.28 \pm 3.05$ & $-1.52 \pm 0.02$ & $13.41 \pm 2.47$ & $-1.48 \pm 0.01$ & $10.30 \pm 2.34$ & $-1.51 \pm 0.04$ & $12.40 \pm 2.23$ \\
\hline $1 \mathrm{Gd}$ & $-1.60 \pm 0.03$ & $10.38 \pm 1.01$ & $-1.49 \pm 0.01$ & $10.26 \pm 1.19$ & $-1.54 \pm 0.01$ & $9.50 \pm 1.03$ & $-1.50 \pm 0.03$ & $10.31 \pm 0.65$ \\
\hline $2 \mathrm{Gd}$ & $-1.61 \pm 0.02$ & $25.88 \pm 2.12$ & $-1.47 \pm 0.03$ & $18.98 \pm 2.39$ & $-1.52 \pm 0.03$ & $10.93 \pm 1.71$ & $-1.51 \pm 0.02$ & $14.41 \pm 1.02$ \\
\hline
\end{tabular}

the resistance of the Hank's solution. $\mathrm{CPE}_{1}$ (constant phase element) and $R_{1}$ describe the corrosion film capacity and resistance, respectively. $\mathrm{CPE}_{2}$ is used to describe the electric double layer capacity between the Hank's solution and the matrix. $R_{2}$ is the charge transfer resistance. $R_{3}$ and $L$ describe the inductive loop, representing the hydrogen evolution. Every parameter value is listed in Table $3 . R_{2}$ reflects the corrosion resistance of an alloy directly. The larger the value of $R_{2}$, the better the corrosion resistance of the alloy. $R_{2}$ value of the $1 \mathrm{Gd}$ alloy was much higher than that of the other alloys, implying that the $1 \mathrm{Gd}$ alloy possessed the best resistance to corrosion.

\section{Discussion}

\subsection{Effects of ECAP Extrusion and Gd Content on Mechanical Properties}

Gd has a high solubility in Mg alloy, which plays important roles in both the solid solution strengthening and second phase strengthening [24]. Severe plastic deformation can also improve the mechanical properties of the $\mathrm{Mg}$ alloys by grain refinement. 

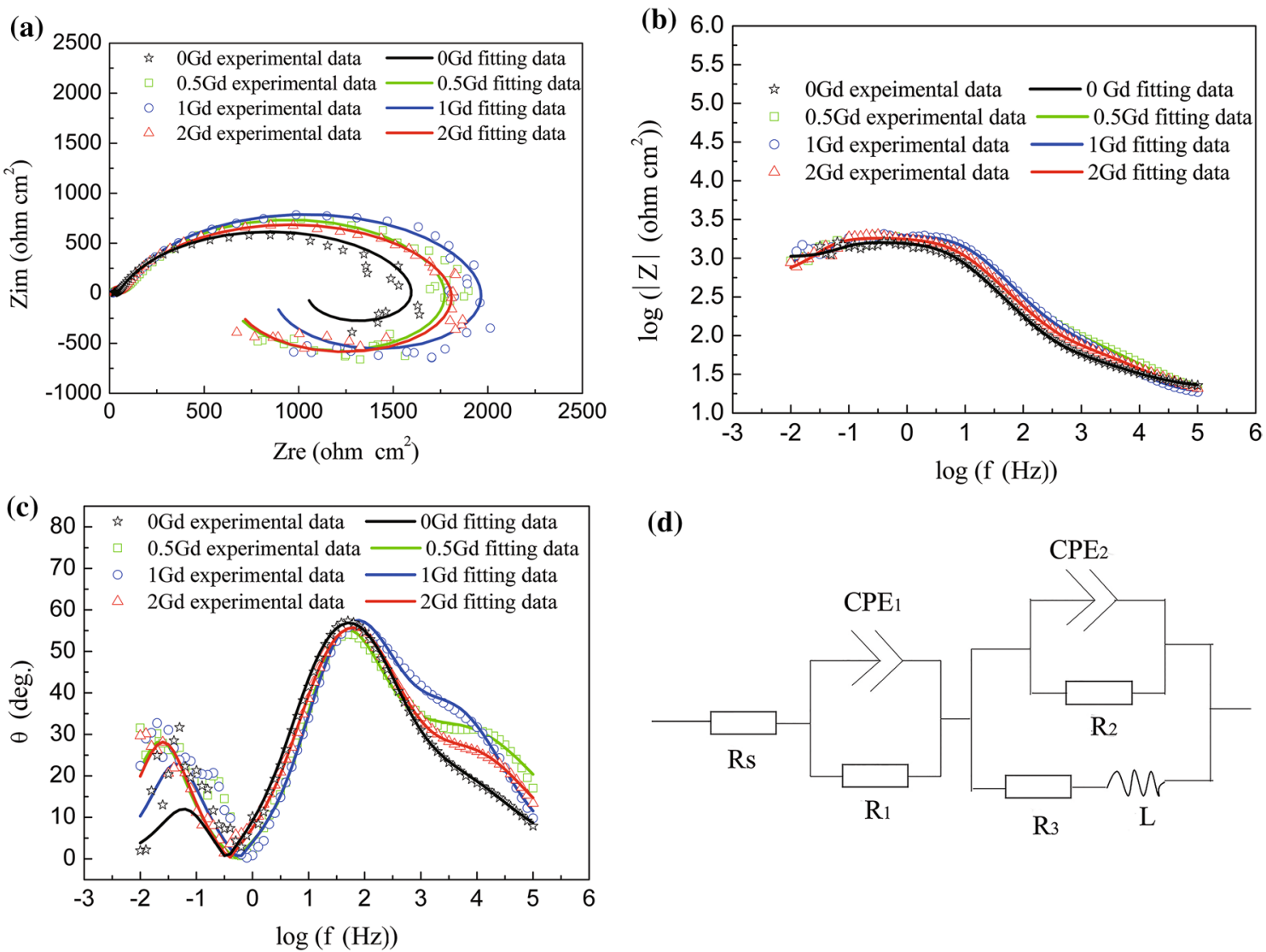

Fig. 14 Impedance curves of the $\mathrm{Mg}-2 \mathrm{Zn}-x \mathrm{Gd}-\mathrm{Zr}$ alloys after four passes extrusion: a Nyquist plots, $\mathbf{b}$ Bode plots of $\log |Z|$ versus $\log f, \mathbf{c}$ Bode plots of phase angle, $\mathbf{d}$ equivalent circuit of the alloys in Hank's solution

Table 3 Fitting results of $\mathrm{Mg}-2 \mathrm{Zn}-x \mathrm{Gd}-\mathrm{Zr}$ alloys immersed in Hank's solution after four passes extrusion

\begin{tabular}{|c|c|c|c|c|c|c|c|c|c|}
\hline \multirow[t]{2}{*}{ Specimens } & \multirow[t]{2}{*}{$R_{\mathrm{s}}\left(\Omega \mathrm{cm}^{2}\right)$} & \multicolumn{2}{|l|}{$\mathrm{CPE}_{1}$} & \multirow[t]{2}{*}{$R_{1}\left(\Omega \mathrm{cm}^{2}\right)$} & \multicolumn{2}{|l|}{$\mathrm{CPE}_{2}$} & \multirow[t]{2}{*}{$R_{2}\left(\Omega \mathrm{cm}^{2}\right)$} & \multirow[t]{2}{*}{$R_{3}\left(\Omega \mathrm{cm}^{2}\right)$} & \multirow[t]{2}{*}{$L\left(\mathrm{H} \mathrm{cm}^{-2}\right)$} \\
\hline & & $\mathrm{Y}_{01}\left(\mathrm{~S} \mathrm{~s}^{n} \mathrm{~cm}^{-2}\right)$ & $n_{1}$ & & $\mathrm{Y}_{02}\left(\mathrm{~S} \mathrm{~s}^{n} \mathrm{~cm}^{-2}\right)$ & $n_{2}$ & & & \\
\hline 0Gd & 19.76 & $1.0 \times 10^{-5}$ & 0.60 & 34.02 & $28.87 \times 10^{-6}$ & 0.80 & $1.59 \times 10^{3}$ & $8.35 \times 10^{3}$ & $2.63 \times 10^{3}$ \\
\hline $0.5 \mathrm{Gd}$ & 13.04 & $6.76 \times 10^{-5}$ & 0.50 & 134.70 & $12.13 \times 10^{-6}$ & 0.90 & $1.64 \times 10^{3}$ & $9.54 \times 10^{3}$ & $0.69 \times 10^{3}$ \\
\hline $1 \mathrm{Gd}$ & 16.91 & $2.40 \times 10^{-5}$ & 0.70 & 73.30 & $12.27 \times 10^{-6}$ & 0.90 & $1.91 \times 10^{3}$ & $7.56 \times 10^{3}$ & $1.32 \times 10^{3}$ \\
\hline $2 \mathrm{Gd}$ & 16.31 & $4.13 \times 10^{-5}$ & 0.60 & 52.90 & $21.32 \times 10^{-6}$ & 0.80 & $1.70 \times 10^{3}$ & $7.56 \times 10^{3}$ & $0.88 \times 10^{3}$ \\
\hline
\end{tabular}

When the Gd content was low, W-phase and I-phase were the main second phases. Moreover, the content of the second phases was low with weak second phase strengthening (Fig. 4). Therefore, UTS, YS, EL and hardness of the $0.5 \mathrm{Gd}$ alloy were low (Fig. 7). With the increase in Gd content (1-2 wt \%), more and more $\mathrm{W}$ phases formed in the alloys. Furthermore, after four passes ECAP extrusion, the second phases were disintegrated into many small particles distributing along the grain boundaries or within the grains. Under this situation, the dispersed second phases inhibited the dislocation movement and thereby enhanced the mechanical properties of the alloys resulting from strong second phase strengthening.
ECAP extrusion plays an important role in improving the mechanical properties of $\mathrm{Mg}$ alloys [25, 26]. With the increase in the extrusion pass, the mechanical properties of the alloys were enhanced obviously due to the grain refinement. For the $1 \mathrm{Gd}$ alloy, compared with the two passes extrusion, UTS, YS and EL after four passes extrusion were increased by about $17 \%, 30 \%$ and $60 \%$, respectively. However, under the same extrusion pass (four passes), there were no obvious differences in mechanical properties among the $0.5 \mathrm{Gd}, 1 \mathrm{Gd}$ and $2 \mathrm{Gd}$ alloys. This indicates that although both Gd content and extrusion pass could influence the mechanical properties of the alloys, extrusion pass played the dominant role. Furthermore, it implied 
that grain refinement strengthening was better than second phases strengthening during the severe plastic deformation. According to the Hall-Petch relation, $\sigma_{0.2}=\sigma_{0}+k d^{-1 / 2}$, the smaller the grain size, the higher the strength. Yu Yoshida et al. [27] found that for AZ31 alloy after ECAP extrusion, the Hall-Petch formula was $\sigma_{0.2}=30+0.17 d^{-1 / 2}$. Due to the higher coefficient $k$ value of AZ31 alloy, the strength was improved obviously after ECAP extrusion. According to our present study, the coefficient $k$ value was 0.25 which was higher than 0.17 ; therefore, it can be inferred that the grain refinement was more beneficial to the strength enhancement of the 2Gd alloys than AZ31 alloy. However, after four passes extrusion, $\langle c+a>$ slip system was activated for the $2 \mathrm{Gd}$ alloy due to the grain refinement and the change of fiber texture to $\{2111\}$. Compared with other $\mathrm{Mg}$ alloys, the texture strength of all the alloys was much lower. The fiber texture softening decreased the grain refinement strengthening. Therefore, the strength of the $2 \mathrm{Gd}$ alloy was not obviously improved compared with the $1 \mathrm{Gd}$ alloy.

Another theory to explain the mechanical properties can be summarized as follows. With increasing Gd content, the amount of Gd rich phase increases. The increased Gd rich phase would contribute to the grain refinement during the extrusion. And the grain refinement helps the redistribution of the Gd rich phase. The redistributed fine Gd phase would handicap the movement of dislocations and contribute to the strength. It was also beneficial to the improvement of elongation. Moreover, the bimodal grain structure also had an effect on the mechanical properties. Wang et al. [28] found that deformation mechanism in the bimodal grainstructured samples was dominated by basal slips in fine grains and twinning in coarse grains. The bimodal structure contributed to the coordinated deformation. Liu et al. [29] found that although the strength of ECAP alloy increased, the increasing range declined with further passes of ECAP, as the size of second phases decreased gradually in bimodal microstructures. It also can be used to explain the strength change of the $\mathrm{Mg}-2 \mathrm{Zn}-x \mathrm{Gd}-0.5 \mathrm{Zr}$ alloys.

\subsection{Effects of ECAP Extrusion and Gd Content on Biodegradable Property}

In $\mathrm{Mg}$ alloys, finely and continuously distributed second phases are beneficial to the improvement of the corrosion resistance, and the reverse will reduce the corrosion resistance [30]. For the as-cast alloys, when the Gd content was $0-1 \mathrm{wt} \%$, the content of the second phases was low and they were uniformly distributed in the alloys. Therefore, the corrosion resistance of the alloys was improved. However, when the Gd content increased, many thick network-like structured second phases formed, which was detrimental to the corrosion resistance of the alloys because of the galvanic effect (Fig. 4). The effects of extrusion pass on the degradable resistance can be explained as follows. Before the extrusion, there were many large and coarse second phases in the alloys. It was detrimental to the corrosion resistance (Fig. 15a). After two passes ECAP extrusion, the second phases were changed from bulk to small particles and their distribution was more uniform. The small and uniform second phases can inhibit the galvanic effect. Besides, the grain size was reduced obviously and the grains were much more uniform than the as-cast alloy (Fig. 15b). Therefore, the corrosion resistance of the alloys was enhanced. However, as further increasing the extrusion pass, the bimodal microstructure formed. The ultra-fine grains distribution was mainly strip-shaped (Fig. 15c). The area of the grain and interphase boundaries in the ultra-fine-grained material was increased. The energy at the ultrafine grains boundaries was high, and therefore corrosion occurred easily at the grain boundaries, leading to the decrease in corrosion resistance of the alloys. These results were in agreement with the study of Kutniy et al. [31]. Furthermore, it is reported that there

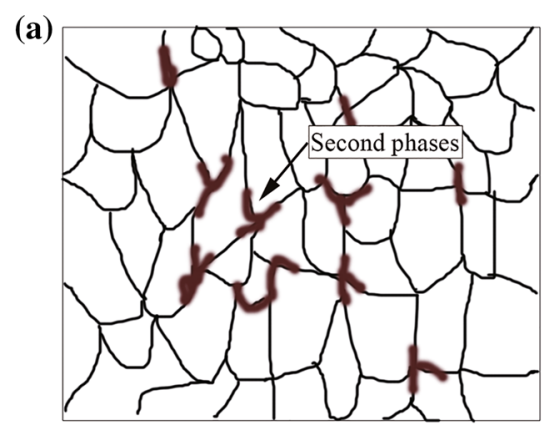

Large second phases and grain size (b)

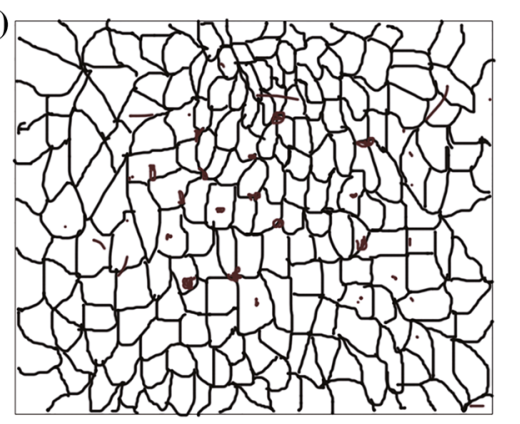

Uniform distribution second phases and fine grain size (c)

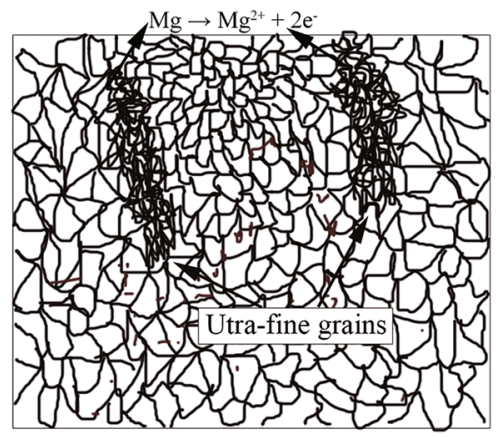

Untra-fine grains formed

Fig. 15 Schematic illustration of the alloy degradation after extrusion: a large second phases and grain size in the as-cast alloy, $\mathbf{b}$ the grain size decreased and the second phases distributed uniformly after two passes extrusion, $\mathbf{c}$ the grain size decreased further and many strip-shaped ultrafine grains formed after four passes extrusion. The corrosion occurred from the ultra-fine grains 
is also strong galvanic effect between the large grains and small grains in $\mathrm{Mg}$ alloys [32]. After four passes extrusion, many strip-shaped ultra-fine grains formed. Strong galvanic effect was created between the large grains and the ultrafine grains, resulting in the decrease in the corrosion resistance. Under the same ECAP extrusion pass, the $1 \mathrm{Gd}$ alloy showed the best corrosion resistance. This was because the distribution of second phases in the $1 \mathrm{Gd}$ alloy was more uniform than other alloys after ECAP extrusion. Another reason might be related to the texture. $\mathrm{Mg}$ grains showed anisotropic corrosion behavior [33]. If the texture was inhibited, the $\mathrm{Mg}$ alloys would exhibit the isotropic corrosion, and therefore the alloys would exhibit uniform corrosion. After the extrusion, the $1 \mathrm{Gd}$ alloy showed the weakest texture (Fig. 6c). Therefore, the texture had the least influence on the corrosion resistance.

\section{Conclusions}

Effects of ECAP extrusion on the microstructure, mechanical properties and biodegradability of $\mathrm{Mg}-2 \mathrm{Zn}-x \mathrm{Gd}-0.5 \mathrm{Zr}$ alloys were studied in this work. Some conclusions can be obtained:

(1) After ECAP extrusion, the grain sizes of the alloys were greatly decreased. Moreover, with the increase in Gd content the grain refinement effect was further enhanced. After four passes extrusion, the grain size of the $2 \mathrm{Gd}$ alloy was about $2 \mu \mathrm{m}$. After extrusion, the distribution of second phases was changed from bulk to small particles.

(2) Both Gd addition and ECAP extrusion pass could improve the mechanical properties of the alloys. However, ECAP extrusion pass played the dominant role due to the grain refinement strengthening.

(3) The corrosion resistance of the alloys was enhanced by adding minor content of $\mathrm{Gd}(0.5-1 \mathrm{wt} \%)$. When the content of Gd was $2 \mathrm{wt} \%$, many second phases formed in the alloys, which was detrimental to the corrosion resistance. Besides, severe plastic deformation could enhance the corrosion resistance to some extent due to the change of the second phase distribution and the grain refinement. Further increase in extrusion pass was harmful to the corrosion resistance as a result of the increment of the grain boundaries.

Acknowledgements This work was financially supported by the Key Program of China on Biomedical Materials Research and Tissue and Organ Replacement (Nos. 2016YFC1101804 and 2016YFC1100604), the Shenyang Key R\&D and Technology Transfer Program (No. Z18-0-027), the National Natural Science Foundation of China (No. 51801220), the Top-notch Academic Programs Project of Jiangsu
Higher Education Institutions (TAPP) and the Priority Academic Program Development of Jiangsu Higher Education Institutions (PAPD).

\section{References}

[1] F. Witte, V. Kaese, H. Haferkamp, E. Switzer, A. Meyer-Lindenberg, C.J. Wirth, H. Windhagen, Biomaterials 26, 3557 (2005)

[2] D.W. Zhao, S.B. Huang, F.Q. Lu, B.J. Wang, L. Yang, L. Qin, K. Yang, Y.D. Li, W.R. Li, W. Wang, S.M. Tian, X.Z. Zhang, W.B. Gao, Z.P. Wang, Y. Zhang, X.H. Xie, J.L. Wang, J.L. Li, Biomaterials 81, 84 (2016)

[3] H. Windhagen, K. Radtke, A. Weizbauer, J. Diekmann, Y. Noll, U. Kreimeyer, R. Schavan, C. Stukenborg-Colsman, H. Waizy, Biomed. Eng. Online 12, 62 (2013)

[4] J. Kang, J.K. Han, H.M. Yang, K.W. Park, H.J. Kang, B.K. Koo, H.S. Kim, Circ. J. 81, 1065 (2017)

[5] H. Li, X. Feng, Y. Peng, R. Zeng, Nanoscale 12, 7700 (2020)

[6] G.L. Song, S.Z. Song, Acta Phys. Chim. Sin. 22, 1222 (2006)

[7] H. Miao, H. Huang, Y. Shi, H. Zhang, J. Pei, G. Yuan, Corros. Sci. 122, 90 (2017)

[8] J. Zhang, S. Liu, R. Wu, L. Hou, M. Zhang, J. Magnes. Alloys 6, 277 (2018)

[9] H. Liu, H. Huang, J.P. Sun, C. Wang, J. Bai, A.B. Ma, X.H. Chen, Acta Metall Sin. -Engl. Lett. 32, 269 (2018)

[10] Y.F. Ding, C.E. Wen, P. Hodgson, Y.C. Li, J. Mater. Chem. B 2, $1912(2014)$

[11] J. Chen, L. Tan, X. Yu, K. Yang, J. Mater. Sci. Technol. 35, 503 (2018)

[12] B. Jiang, Q. Xiang, A. Atrens, J. Song, F. Pan, Corros. Sci. 126, 374 (2017)

[13] Y. Feng, S. Zhu, L. Wang, L. Chang, Y. Hou, S. Guan, Bioact. Mater. 3, 225 (2018)

[14] Y.C. Wan, S.Y. Xu, C.M. Liu, Y.H. Gao, S.N. Jiang, Z.Y. Chen, Mater. Lett. 213, 274 (2018)

[15] H.B. Henderson, V. Ramaswamy, A.E. Wilson-Heid, M.S. Kesler, J.B. Allen, M.V. Manuel, J. Mech. Behav. Biomed. Mater. 80, 285 (2018)

[16] C.Z. Zhang, S.J. Zhu, L.G. Wang, R.M. Guo, G.C. Yue, S.K. Guan, Mater. Des. 96, 54 (2016)

[17] H. Liu, H. Huang, C. Wang, J. Sun, J. Bai, F. Xue, A.B. Ma, X.B. Chen, JOM 71, 3314 (2019)

[18] B. Du, Z. Hu, J. Wang, L. Sheng, H. Zhao, Y. Zheng, T. Xi, Bioact. Mater. 5, 219 (2020)

[19] B.N. Du, Z.P. Xiao, Y.X. Qiao, L. Zheng, B.Y. Yu, D.L. Xu, L.Y. Sheng, J. Alloys Compd. 775, 990 (2019)

[20] B.R. Sunil, T.S.S. Kumar, U. Chakkingal, V. Nandakumar, M. Doble, V.D. Prasad, M. Raghunath, Mater. Sci. Eng. C 59, 356 (2016)

[21] W. Zhang, L. Tan, D. Ni, J. Chen, Y. Zhao, L. Liu, C. Shuai, K. Yang, A. Atrens, M. Zhao, J. Mater. Sci. Technol. 35, 777 (2019)

[22] Y. Zong, G.Y. Yuan, X.B. Zhang, L. Mao, J.L. Niu, W.J. Ding, Mater. Sci. Eng. B 177, 395 (2012)

[23] D.K. Xu, E.H. Han, Prog. Nat. Sci. 22, 364 (2012)

[24] S.Q. Yin, Z.Q. Zhang, X. Liu, Q.C. Le, Q. Lan, L. Bao, J.Z. Cui, Mater. Sci. Eng. A 695, 135 (2017)

[25] P. Minarik, R. Kral, J. Cizek, F. Chmelik, Acta Mater. 107, 83 (2016)

[26] P. Minárik, R. Král, J. Pešička, S. Daniš, M. Janeček, Mater. Charact. 112, 1 (2016)

[27] Y. Yoshida, L. Cisar, S. Kamado, Y. Kojima, Mater. Trans. 44, 468 (2003)

[28] B. Wang, D. Xu, L. Sheng, E. Han, J. Sun, J. Mater. Sci. Technol. 35, 2423 (2019) 
[29] H. Liu, J. Ju, X. Yang, J. Yan, D. Song, J. Jiang, A. Ma, J. Alloys Compd. 704, 509 (2017)

[30] G.L. Song, A. Atrens, M. Dargusch, Corros. Sci. 41, 249 (1999)

[31] K.V. Kutniy, I.I. Papirov, M.A. Tikhonovsky, A.I. Pikalov, S.V. Sivtzov, L.A. Pirozhenko, V.S. Shokurov, V.A. Shkuropatenko, Materialwiss. Werkstofftech. 40, 242 (2009)
[32] R.C. Zeng, K.U. Kainer, C. Blawert, W. Dietzel, J. Alloys Compd. 509, $4462(2011)$

[33] G.L. Song, JOM 64, 671 (2012) 